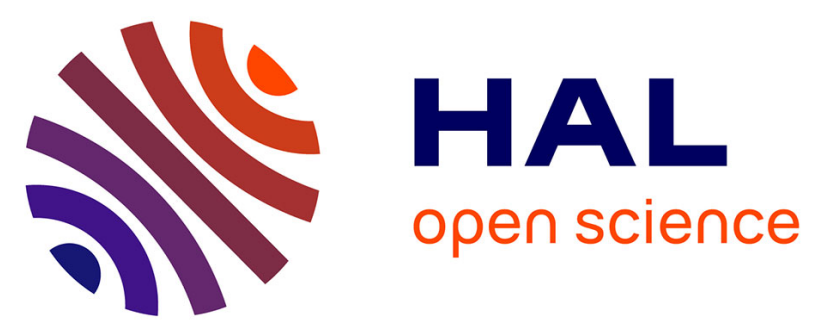

\title{
PHYSIOLOGICAL STRESS MONITORING USING SODIUM ION POTENTIOMETRIC MICROSENSORS FOR SWEAT ANALYSIS
}

Arnaud Cazalé, William Sant, Frédéric Ginot, Jean-Claude Launay, Gustave Savourey, Frédéric Revol-Cavalier, Jean-Michel Lagarde, Didier Heinry, Jérôme Launay, Pierre Temple-Boyer

\section{To cite this version:}

Arnaud Cazalé, William Sant, Frédéric Ginot, Jean-Claude Launay, Gustave Savourey, et al.. PHYSIOLOGICAL STRESS MONITORING USING SODIUM ION POTENTIOMETRIC MICROSENSORS FOR SWEAT ANALYSIS. Sensors and Actuators B: Chemical, 2016, 225, pp. 1-9. 10.1016/j.snb.2015.10.114 . hal-01225639

\section{HAL Id: hal-01225639 \\ https://hal.science/hal-01225639}

Submitted on 6 Nov 2015

HAL is a multi-disciplinary open access archive for the deposit and dissemination of scientific research documents, whether they are published or not. The documents may come from teaching and research institutions in France or abroad, or from public or private research centers.
L'archive ouverte pluridisciplinaire HAL, est destinée au dépôt et à la diffusion de documents scientifiques de niveau recherche, publiés ou non, émanant des établissements d'enseignement et de recherche français ou étrangers, des laboratoires publics ou privés. 


\title{
PHYSIOLOGICAL STRESS MONITORING USING SODIUM ION POTENTIOMETRIC MICROSENSORS FOR SWEAT ANALYSIS
}

A. Cazale ${ }^{1,2,3}$, W. Sant ${ }^{1}$, F. Ginot ${ }^{1}$, J-C. Launay ${ }^{4}$, G. Savourey ${ }^{4}$, F. Revol-Cavalier ${ }^{5}$, J.M. Lagarde ${ }^{6}$, D. Heinry ${ }^{7}$, J. Launay ${ }^{2,3}, \underline{\text { P. Temple-Boyer }}{ }^{2,3}$

1) HEMODIA SA, Rue du chêne vert, BP88205, F-31682 Labège, France

2) CNRS, LAAS, 7 avenue du colonel Roche, F-31400 Toulouse, France

3) Université de Toulouse; UPS; LAAS; F-31400 Toulouse, France

4) IRBA-CRSSA, antenne de La Tronche, 24 avenue des maquis du Grésivaudan, F-38702 La Tronche Cedex, France

5) CEA, LETI, MINATEC Campus, Technologies for Healthcare and Biology division, F-38054 Grenoble, France

6) Centre de Recherche sur la Peau, Laboratoire Pierre Fabre Dermo-Cosmétique, 31025 Toulouse, France

7) PAUL BOYE TECHNOLOGIES, 1095 chemin de la riverotte, F-31860 Labarthe sur Lèze, France

\begin{abstract}
In the frame of sweat analysis, two technologies, based on either ISE or ISFET devices, were developed for the implementation of pNa potentiometric microsensors. Both of them demonstrated good sodium ion $\mathrm{Na}^{+}$detection properties with a global sensitivity of around $110 \mathrm{mV} / \mathrm{pNa}$ in $\mathrm{NaCl}$ based solutions due to the use of an integrated " $\mathrm{Ag} / \mathrm{AgCl}$ ink" pseudo-reference electrode. Then, in order to deal with in-vivo analysis of sweat natremia, a physiological sweatband prototype was
\end{abstract}


developed, consisting of pNa-ISE and pNa-ISFET electronic detection modules as well as a textilebased sweat pump. Finally, sweating process was studied during series of experiments on twentyfive healthy consenting subjects. The sodium ion concentration $\left[\mathrm{Na}^{+}\right]$was successfully monitored in sweat during various heat exposures, demonstrating a global increase with exercise trial duration. Furthermore, a strong correlation was found between the sweat $\left[\mathrm{Na}^{+}\right]$concentration and the subject's internal temperature $\theta$, allowing monitoring the subject's heat stress state. All in all, the relevance of the $\mathrm{Na}^{+}$ion analysis was demonstrated for the physiological stress monitoring and $\mathrm{pNa}$ potentiometric microsensors were shown to be very promising for the development of smart sweatbands.

Keywords: potentiometric sensor, ISE, ISFET, $\mathrm{Na}^{+}$ion detection, sweat analysis, physiological stress 


\section{Introduction}

In the human body, the balance between heat production and heat losses is continuously being regulated by sweat evaporation on the skin surface in order to prevent heat stroke [1]. As a result, sweating is essential for thermoregulation. Highly variable sweating rates were observed, mainly depending on physical activity and climate conditions [2-4]. Sweat consists mostly in water (99\%) but contains many different chemical and biochemical compounds: water-based and mineral ions, lactate ion, ammonia, urea, uric and ascorbic acids, amino-acids, lipids and/or proteins [2,5-13]. According to these different works, sweat composition varies considerably from individual to individual. Influential parameters were associated to age, sex, race, genotype and of course heat stress, either resulting from climate conditions and/or levels of physical exercise. Among the different chemical and biochemical species present in sweat and/or on the skin surface, sodium $\left(\mathrm{Na}^{+}\right)$and chloride $\left(\mathrm{Cl}^{-}\right)$ions, i.e. $\mathrm{NaCl}$ salts, were more specifically studied since both ions play key roles in the ionic equilibrium of body fluids. Focusing on sodium ion $\mathrm{Na}^{+}$, it was shown that sweat $\left[\mathrm{Na}^{+}\right]$concentration depends widely on individual physiologies and varies with sweating conditions $[2,5,6,8,14-16]$. In fact, assuming that sweat conductivity depends mainly on $\mathrm{Na}^{+} / \mathrm{Cl}^{-}$ion concentrations, strong correlations were evidenced between heart rate, sub-lingual temperature, sweat rate and sweat sodium concentration [17]. Consequently, the sodium ion $\mathrm{Na}^{+}$was considered as a potential marker for heat stress monitoring.

In the frame of point of care applications, $\mathrm{Na}^{+}$potentiometric sensors, such as ion-sensitive electrodes (ISE) and ion-sensitive field effect transistors (ISFET), were preferentially studied using different ion-sensitive membranes. They can be either inorganic, focusing on the use of sodium aluminosilicate $\mathrm{Na}-\mathrm{AlSi}_{3} \mathrm{O}_{8}[18,19]$, either organic, emphasizing the use of sodium ionophores and polymers [20,21]. As far as polymers are concerned, poly-vinyl-chloride (PVC) [22-26], polyurethane (PY) [27,28], polypyrolle (PPy) [29], polysiloxane (PSX) [30-33] and fluoropolysiloxane (FPSX) [34,35] were studied, demonstrating fundamental differences in terms 
of physical properties and integration processes. Alternatively, the use of numerous sodium ionophores enabled the development of $\mathrm{Na}^{+}$-sensitive ISE and ISFET microdevices with quasinernstian potentiometric responses.

Even if sweat samples collection is relatively easy, measurement in sweat remains uncertain because of physiological discrepancy between human subjects as well as differences between sampling techniques and/or experimental conditions. Therefore, in order to attain skin chemical analysis, several approaches were proposed [36]. Integrated electrochemical microcells were developed for skin antioxidant properties but, as epidermal contact was limited to low durations, skin hydrolipidic film, rather than sweat, was deliberately analysed [37]. In order to activate sweat production, iontophoresis was successfully used for the transdermal ethanol measurement due to a miniaturized amperometric biosensor [38]. Nevertheless, such technique is not compatible with sweat ambulatory monitoring systems. Indeed, in order to thoroughly deal with sweat analysis, long duration epidermal contact is required. This goal was reached by developing flexible/textile technologies and smart tattoos. Thus, using a stretchable impedimetric microsensor incorporating a porous substrate to collect sweat, the in-situ monitoring of sweat dielectric properties and production rate was demonstrated [39]. Epidermal tattoos were also developed for the continuous sweat monitoring, based on amperometric detection of antioxidant species [40,41], pH measurement [42] and potentiometric pNa detection [43]. This last work should be highlighted since it showed that sweat $\mathrm{Na}^{+}$concentration increases during physical exercise. However, since these technologies are qualified as temporary, their capacity to deal with high sweat production rates and volumes for long-term skin analysis was not fully demonstrated. This is not the case for smart physiological sweatbands. Consequently, a wearable sensing system was developed, integrating a textile-based fluid handling system for sweat collection and transport as well as conductivity, $\mathrm{pH}$ and $\mathrm{pNa}$ sensors $[44,45]$. As previously demonstrated, the sweat natremia was shown to increase during an exercise trial, highlighting the vital role of $\mathrm{Na}^{+}$ion in human physiology. 
Our interest lies in the safety of first responders (soldiers, fire fighters,...) in their everyday rescue actions. In this frame, the internal temperature monitoring is crucial for preventing hyperthermia and similar physiological threats. However, the use of rectal or tympanic temperature probes is not conceivable and standard body or skin temperature sensors do not give effective results for obvious reasons: heavy gears, external heat stresses, physiological inadequacies,... As a result, an indirect measurement of internal temperature should be established, and sweat natremia monitoring appears to be the most promising solution for this matter. Thus, this paper presents the development of a wearable sweatband integrating a textile-based pump to collect and deliver sweat samples as well as ISE and ISFET microsensors to monitor sodium ion $\mathrm{Na}^{+}$concentration in sweat during heat stress tests. pNa microsensors detection performances are analysed, the fabrication procedure of a complete $\mathrm{Na}^{+}$-monitoring sweatband is described, sweat monitoring is demonstrated during in-vivo experiment on human subjects, and correlations between sweat sodium ion concentration $\left[\mathrm{Na}^{+}\right]$and internal temperature $\theta$ are finally examined.

\section{Experimental}

Two technologies based on potentiometric detection principles were compared for the development of $\mathrm{pNa}$ potentiometric microsensors: ion-sensitive electrodes (ISE) at CEA-LETI (Grenoble, France) and ion-sensitive field effect transistors (ISFET) at LAAS-CNRS (Toulouse, France).

\section{1 pNa-ISE microsensors fabrication}

The developed electrochemical sensor consists in a host ionophore incorporated in a conducting polymeric membrane. The targeted ion complexation with the host molecule leads to a modification of the electrochemical potential. This modification is measured by potentiometry 
through the evolution of the open circuit potential (OCP). In this application, the electrochemical measurement cell was comprised of three silver working electrodes (ET1, ET2 and ET3) to assure measurement reproducibility [45]. These ISE microdevices used an "Ag/AgCl ink" pseudoreference electrode integrated on the pNa-ISFET detection module (see section 2.2 hereafter).

To fabricate the pNa-ISE sensor (Fig. 1), a poly-vinyl-chloride (PVC) platform (volume: $16 \times$ $8 \times 4 \mathrm{~mm}^{3}$ ), containing a cavity, was designed and glued on a dedicated substrate. Then, the empty cavity was filled with a mix of $0.1 \mathrm{M} \mathrm{NaCl}$ solution and glycerol $(25 \%$ and $75 \%$ in weight respectively). Finally, $90 \mathrm{mg}$ PVC, $20 \mathrm{mg}$ ETH500, $20 \mathrm{mg}$ 4-tert-butylcalix[4]arene-tetra-acetic acid tetraethyl ester and $201 \mu \mathrm{L}$ of bis(2-ethylhexyl)adipate solution were dissolved in $1.5 \mathrm{ml}$ of tetrahydrofuran (all the compounds were purchased from Sigma Aldrich). This solution was dropcasted directly on the filling solution at the top of the PVC platform. Over a night at room temperature, after solvent evaporation, a $\mathrm{Na}^{+}$-sensitive PVC membrane was automatically sealed on the PVC platform. So, detection modules involving three pNa-ISE with a common solid/liquid interface were successfully developed (Fig. 2).

\section{2 pNa-ISFET microsensors fabrication}

The $\mathrm{SiO}_{2} / \mathrm{Si}_{3} \mathrm{~N}_{4}-\mathrm{pH}$-ChemFET technology used was already presented in previous works, demonstrating quasi-nernstian $\mathrm{pH}$ responses (sensitivity around $53 \mathrm{mV} / \mathrm{pH}$ ), detection accuracy around $1 \mathrm{mV}$ or $0.02 \mathrm{pH}$, maximal drift lower than $5 \mathrm{mV} /$ day and lifetime higher than four months [46]. This technology was successfully adapted to sodium $\mathrm{Na}^{+}$ion detection using fluoropolysiloxane (FPSX) based ion-sensitive layers [35]. Consequently, P-well, N-channel, $\mathrm{SiO}_{2} / \mathrm{Si}_{3} \mathrm{~N}_{4}$-gate, $\mathrm{pH}$-sensitive chemical field effect transistors ( $\mathrm{pH}$-ChemFET) were fabricated on 6-inch, (100)-oriented, N-type (500 $\Omega . \mathrm{cm})$ silicon wafers in a silicon foundry in order to assure mass fabrication at low cost, with high reproducibility and high fabrication yield. Then, "Smart cards" techniques were used in order to reach automated, mass fabrication/packaging of detection 
microdevices (called "ISFET detection module" hereafter) integrating two pH-ChemFET chips (size: $2.1 \times 1.6 \mathrm{~mm}^{2}$ ) and an "Ag/AgCl ink" (purchased from Gwent group) pseudo-reference electrode (surface: $\sim 5 \mathrm{~mm}^{2}$ ). Finally, "drop on demand" ink jet process was used for the controlled deposition of FPSX-based, $\mathrm{Na}^{+}$-sensitive membranes using $10 \mathrm{mg}$ of "4-tert-butylcalix[4]arenetetra-acetic acid tetraethyl ester" sodium ionophore and $5 \mathrm{mg}$ of "sodium tetrakis [3,5bis(1,1,1,3,3,3-hexafluoro-2-methoxy-2-propyl)phenyl]borate trihydrate" ionic additive (all the chemical compounds were purchased from Sigma-Aldrich) [35]. Consequently, detection modules involving a pNa-ISFET, a $\mathrm{pH}-\mathrm{ChemFET}$ and " $\mathrm{Ag} / \mathrm{AgCl}$ ink" pseudo-reference electrode were successfully developed (Fig. 3).

\subsection{Development of a physiological sweatband for $\mathrm{Na}^{+}$ion concentration analysis in sweat}

To deal with the final objective related to sweat in-vivo analysis, a physiological sweatband prototype was conceived and fabricated. First of all, the ISE and ISFET detection modules and their associated EPROM (SOIC8 from Conrad company) measurement interfaces were connected on a Kapton-based flexible substrate. An Analog Device ADT7301 temperature probe was finally connected on the electronic platform to take into account sweat temperature during the electrochemical measurement (Fig. 4). Then, a hydrophilic, textile-based sweat pump was also developed. It involves a sampling zone (surface: $5 \times 3 \mathrm{~cm}^{2}$, thickness: $2.4 \mathrm{~mm}$ ) and a transfer zone (surface: $2 \times 1 \mathrm{~cm}^{2}$, thickness: $0.8 \mathrm{~mm}$ ) in order to collect and transport sweat towards sensor sensitive surfaces using capillary forces, as well as a storage zone (surface: $5 \times 3 \mathrm{~cm}^{2}$, thickness: 5 $\mathrm{mm}$ ) to assure an efficient pumping capacity (Fig. 5). The sampling and transfer zones were both made of non-woven polypropylene with a trilobal fiber structure. Their absorption properties were characterized by an initial "dry" regime with a high capillary velocity $(\sim 1.5 \mathrm{~mm} / \mathrm{s})$ and a steady state "wet" regime with a lower one $(\sim 0.2 \mathrm{~mm} / \mathrm{s})$, enabling a global capillarity absorption of around

0.11 meter in four minutes. For the storage zone, the material used was based on 
polyester/polyacrylate fibers, assuring a water absorption rate of $300 \%$ in weight (or $240 \%$ in thickness). According to these characteristics, delay associated to the sweat transport towards the sensor sensitive surface was estimated at around two minutes, i.e. significantly lower than the sweating physiological delay (10-15 minutes depending on subjects). Finally, the functional integration of the different sweat analysis elements was performed on the basis of a chest strap for heart rate monitoring (Fig. 6).

\subsection{In vitro electrochemical measurements}

A portable electronic board was developed as an interface for the electrochemical sensors. This electronic part is responsible for signal acquisition and signal processing in order to convert the electrical information to sodium ion $\mathrm{Na}^{+}$concentration. This prototype consists of analogical parts (regulation, generators, commutation matrix) and control blocks (microcontroller MSP430F1611 pulsated at $8 \mathrm{MHz}$ ), integrating software for communication and signal processing. In-vitro electrical measurements were performed by biasing the solution to the mass $\left(\mathrm{V}_{\text {reference }}=0 \mathrm{~V}\right)$ due to the "Ag/AgCl ink" pseudo-reference electrode integrated on the pNa-ISFET detection module [35]. Both detection modules, i.e. pNa-ISE and pNa-ISFET, were biased in the same way.

Concerning the ISE microsensor, the open circuit potential (OCP) was measured by determining the potential difference between the $\mathrm{Na}^{+}$-sensitive working electrode and the $\mathrm{Ag} / \mathrm{AgCl}$ pseudo-reference electrode when no current is applied. An electronic board (input impedance: $>0.3$ G $\Omega$ ) recorded finally this OCP value in order to compare it with calibration curves using a 12-bit analog-to-digital converter.

For the ISFET microsensor, the gate-source voltage $\mathrm{V}_{\mathrm{GS}}$ of the pNa-ISFET microdevice was monitored using the "source-drain follower" electronic measurement interface, i.e. working with constant drain-source voltage $\mathrm{V}_{\mathrm{DS}}$ and drain-source current $\mathrm{I}_{\mathrm{DS}}$ (typically $\mathrm{V}_{\mathrm{DS}}=2 \mathrm{~V}$ and $\mathrm{I}_{\mathrm{DS}}=0.1$ $\mathrm{mA}$ ) in order to reach saturation mode. In both cases, a specific data treatment was developed: an 
analog-to-digital converter sampled the output voltage useful signal at $1 \mathrm{~Hz}$ and a microprocessor was finally responsible for an average procedure every five seconds. The latter was introduced to improve the signal to noise ratio (measurement accuracy: $1 \mathrm{mV}$ ), leading finally to a measurement display with a $0.2 \mathrm{~Hz}$ sampling frequency.

Sodium ion $\mathrm{Na}^{+}$detection properties were studied for each electrochemical microsensor using these measurement setups. Concerning ISE devices, pNa measurements performances were only tested in solutions with sodium chloride $\mathrm{NaCl}$ concentrations corresponding to the physiological range in sweat $\left(10^{-2}\right.$ to $\left.10^{-1} \mathrm{M}\right)$. For ISFET, they were tested in lithium acetate solutions $\left(\mathrm{CH}_{3} \mathrm{COOLi} 0.1 \mathrm{M}\right)$ with various concentrations of sodium chloride $\mathrm{NaCl}$ (range: $10^{-5}$ to $10^{0} \mathrm{M}$ ).

\subsection{In vivo physiological measurements}

Twenty-five young healthy subjects participated in the study after they went through clinical exam and signed an official consent to the experimental protocol (approved by the Ethics committee of Grenoble University). Their biometrical characteristics are given in Table 1. They underwent three heat stress tests in climatic chamber (IRBA - Antenne CRSSA, La Tronche, France) in order to stimulate sweating at different levels and through different ways: sweating test (SWT), passive controlled hyperthermia test (PCHT) and active controlled hyperthermia test $(\mathrm{ACHT})$.

SWT is a passive heat test [47]. The subject at rest was submitted during 1.5 hour to an external dry heat load (dry air temperature $=$ radiant temperature $=$ ambient temperature $=45-50^{\circ} \mathrm{C}$; relative humidity: $<10 \%$; air speed: $=0.8 \mathrm{~m} / \mathrm{s}$ ) in order to stimulate the sweating response at a level that assures a new thermal equilibrium as heat losses (due to evaporation of sweat) counterbalance the external heat load of the climatic chamber. The aim of the PCHT is to induce a rise in internal temperature up to $39^{\circ} \mathrm{C}$ in 1.5 hour only by changes in the climatic environment (ambient temperature: $45-50^{\circ} \mathrm{C}$ and $20 \%<$ relative humidity $<80 \%$; air speed: $=0.8 \mathrm{~m} / \mathrm{s}$ ) without any 
physical exercise. The subject was strictly at rest, wearing airtight protective clothing (purchased from TYVEK ${ }^{\circledR}$ Classic, DuPont France, Puteaux, France). Such high ambient temperature induces an external heat load and a high relative humidity microclimate, impairing thermolysis that finally leads to a rise in internal temperature. Lastly, ACHT leads to the same rise in internal temperature for the same duration as in PCHT (internal temperature of $39^{\circ} \mathrm{C}$ reached in 1.5 hour). Here, the subject, dressed as in PCHT, underwent a walk on a treadmill (speed: $4 \mathrm{~km} / \mathrm{h}$, slope: $4 \%$ ) inducing an internal heat load combined with an external heat load due to the environmental climatic conditions (ambient temperature: $30-40^{\circ} \mathrm{C}$ and $20 \%<$ relative humidity $<80 \%$ ). Before each test (see above), subjects lied down and rested during 1.5 hour inside the climatic chamber at thermoneutrality (ambient temperature: $28-30^{\circ} \mathrm{C}$ and relative humidity: $40-50 \%$ ) in order to be in the same thermo-physiological state before each test, especially without sweating. The target internal temperature of $39^{\circ} \mathrm{C}$ was chosen since it is the highest possible safety level for the subjects in the specified experimental heat exposure conditions. This target level also allowed each subject to produce enough sweat for samples collection, taking into account differences between physiological capabilities.

During ACHT test, ten subjects wore also the physiological sweatband dedicated to continuous monitoring of sodium ion concentration $\left[\mathrm{Na}^{+}\right]$in sweat (see section 2.3) (Fig. 6). Internal temperature $\theta$ was continuously measured by a rectal probe equipped with a calibrated $\mathrm{Cu}-$ $\mathrm{Ct}$ thermocouple (measurement accuracy: $\pm 0.05^{\circ} \mathrm{C}$, see hereafter) and recorded every 10 seconds. Sweat was collected with the modified Brisson method [48] into two hand-made pockets made of Opsite transparent adhesive film (Smith \& Nephew, London, GB) and impermeable Parafilm M (Bemis, Wisconsin, USA) placed on the abdomen at either side of the umbilicus. The skin was carefully cleaned with alcohol, deionized water and sterile compresses before sweat pocket positioning. The surface of each pocket in contact with skin was of $10 \times 10 \mathrm{~cm}^{2}$. Each of them was equipped with a miniature pipe that is used to withdraw sweat easily. Sweat was first collected after 35 minutes and then every 20 minutes in order to have sufficient volumes for biochemical analyzes. 
In each sample, a mix of sweat was collected from the two pockets (volume: 1 to $2.5 \mathrm{~mL}$ every 20 minutes) and $\mathrm{Na}^{+}$and $\mathrm{Cl}^{-}$ion concentrations were measured online using a calibrated automated analyzer (Roche Hitachi 912 chemistry analyzer) that consisted of three ion-sensitive electrodes (measurement accuracy: $\pm 0.02 \mathrm{pNa}$ or $\mathrm{pCl}$ ). The subjects were also equipped with eleven $\mathrm{Cu}-\mathrm{Ct}$ thermocouples and other specific sensors to measure continuously skin temperature in ten different sites, tympanic temperature (i.e. internal temperature $\theta$ ) as well as heart rate and metabolic heat production. The different thermocouples used were T-type, copper-constantan $(\mathrm{Cu}-\mathrm{Ct})(\mathrm{JD}$ Mesures, La Seyne sur Mer, France) calibrated using a specific bath (WIKA CTB9210, WIKA France, Eragny sur Oise, France), and a Pt100 reference thermometer (PHP602, Ris Orangis, France), with measurement accuracy of $\pm 0.05^{\circ} \mathrm{C}$. Lastly, the body mass of the subjects was continuously measured during all three tests, not only during exercise, but also before and after.

\section{Results and discussion}

Since both potentiometric microsensors, i.e. pNa-ISE and pNa-ISFET were associated with an " $\mathrm{Ag} / \mathrm{AgCl}$ ink" pseudo-reference electrode whose potential is also sensitive to chloride ion $\mathrm{Cl}$ concentration (see hereafter), a global detection sensitivity $\mathrm{s}_{0}$ will be defined while taking into the different sensitivities interfering in the measurement chain.

\subsection{In-vitro measurement}

The validation of the pNa-ISE detection module consisted in determining its sensitivity towards a $\mathrm{Na}^{+}$ion concentration variation (estimation for three different devices). As shown in Fig. 7, we observed a linear correlation between $\mathrm{pNa}$ and $\mathrm{OCP}$ values. Due to the use of an "Ag/ $\mathrm{AgCl}$ ink" pseudo-reference electrode and NaCl-based test solutions (see hereafter), the pNa-ISE sensor 
response was characterized by a global sensitivity $\mathrm{s}_{0}$ of around $110 \pm 5 \mathrm{mV} / \mathrm{pNa}$ in the range of 10 to $100 \mathrm{mM}$, corresponding to the typical sodium ion concentration in sweat $[44,49]$.

The pNa-ISFET microsensor was already studied and optimized, demonstrating linear responses (detection sensitivity of $55 \mathrm{mV} / \mathrm{pNa}$ ) in the $[0-4] \mathrm{pNa}$ range, good selectivity towards potassium ion $\left(\mathrm{K}_{\mathrm{Na}+/ \mathrm{K}+} \approx 10^{-3}\right)$ as well as no $\mathrm{pH}$ interferences in the [2-9] $\mathrm{pH}$ range [35]. As a result, its characterization was here limited to its analytical response to $\mathrm{pNa}$. As previously shown, $\mathrm{pNa}$ ISFET detection modules were characterized by a linear response (global sensitivity $\mathrm{s}_{0}$ estimated for ten different sensors: $110 \pm 5 \mathrm{mV} / \mathrm{pNa}$ ) in the $[0-5] \mathrm{pNa}$ range (Fig. 8).

Thus, both pNa microsensors were characterized by a global sensitivity of $110 \mathrm{mV} / \mathrm{pNa}$. Such high sensitivity is only related to the use of an " $\mathrm{Ag} / \mathrm{AgCl}$ ink" pseudo-reference electrode and NaCl-based solutions. Indeed, from a theoretical point of view and according to our measurement interface, the detection module output voltage $\mathrm{V}_{\text {out }}$ is given by:

$$
\mathrm{V}_{\text {out }}=\mathrm{V}_{\text {offset }}+\mathrm{s}_{\mathrm{pNa}-\text { sensor }} \mathrm{pNa}+\mathrm{s}_{\mathrm{Ag} / \mathrm{AgCl}} \mathrm{pCl}
$$

where $\mathrm{V}_{\text {offset }}$ is the constant parameter depending on the sensor technology and the measurement interface, $\mathrm{s}_{\mathrm{pNa}-\text { sensor }}$ is the pNa-sensor sensitivity to sodium ions and $\mathrm{s}_{\mathrm{Ag} / \mathrm{AgCl}}$ is the sensitivity to chloride ions of the $\mathrm{Ag} / \mathrm{AgCl}$ integrated electrode.

Since NaCl-based solutions were used, the concentrations of sodium $\mathrm{Na}^{+}$and chloride $\mathrm{Cl}^{-}$ ions should be equal, i.e. $\mathrm{pNa}=\mathrm{pCl}$. As a result, the output voltage global sensitivity $\mathrm{s}_{0}$ is expected to be roughly the sum of $\mathrm{s}_{\mathrm{pNa}-\text { sensor }}$ and $\mathrm{s}_{\mathrm{Ag} / \mathrm{AgCl}}$ according to:

$$
\mathrm{V}_{\text {out }}=\mathrm{V}_{\text {offset }}+\left(\mathrm{s}_{\mathrm{pNa} \text {-sensor }}+\mathrm{s}_{\mathrm{Ag} / \mathrm{AgCl}}\right) \mathrm{pNa}
$$

Since the $\mathrm{s}_{\mathrm{pNa}-\text { sensor }}$ and $\mathrm{s}_{\mathrm{Ag} / \mathrm{AgCl}}$ sensitivities were estimated to $55 \mathrm{mV}$ per decade in previous works [35], a global detection sensitivity of $110 \mathrm{mV} / \mathrm{pNa}$ should be obtained. Experimental results 
confirmed this theoretical approach (Fig. 7 and 8). According to them, the potentiometric analytical responses of the different $\mathrm{pNa}$-sensor technologies were finally given by:

- pNa-ISE: $\mathrm{V}_{\text {out }}(\mathrm{mV}) \approx 110 \mathrm{pNa}-218$

- pNa-ISFET: $\mathrm{V}_{\text {out }}(\mathrm{mV}) \approx 110 \mathrm{pNa}+1230$

\subsection{Correlation between $\mathrm{Na}^{+}$ion concentration in sweat and internal temperature}

For different subjects and considering the SWT, PCHT and ACHT tests, a correlation was established between the sweat sodium ion concentration $\left[\mathrm{Na}^{+}\right]$measured in-vitro and the internal temperature $\theta$ (Fig. 9). In most cases (23 out of 25 subjects), a linear relation was demonstrated:

$$
\left[\mathrm{Na}^{+}\right]=\mathrm{a} \theta+\mathrm{b}
$$

Nevertheless, since a and b parameters were different for each subject, a relationship between them was investigated. According to Fig. 10, it appeared that they are linearly correlated:

$$
\text { -b }=\mathrm{a} \theta^{*} \quad \text { with: } \theta^{*} \approx 37.0^{\circ} \mathrm{C}
$$

This linearity is not related to human physiology but to a mathematical artefact. It is due to the very low internal temperature relative variations $\Delta \theta / \theta$ compared to the sodium concentration variations $\Delta\left[\mathrm{Na}^{+}\right] /\left[\mathrm{Na}^{+}\right]$. Nevertheless, according to equations (5) and (6), a direct correlation between the sweat sodium ion concentration $\left[\mathrm{Na}^{+}\right]$and the internal temperature $\theta$ can be written as following:

$$
\left[\mathrm{Na}^{+}\right]=\mathrm{a}\left(\theta-\theta^{*}\right)
$$


Whatever the subject, sweating does not occur immediately but 10-15 minutes after the beginning of the exercise trial. Consequently, it takes approximately 15-20 minutes to collect $1 \mathrm{~mL}$ sweat volume. For these very first sweat samples, physiological differences are responsible for a wide range of sodium concentration $\left[\mathrm{Na}^{+}\right]_{0}$ (from 14 to $76 \mathrm{mM}$ ). On the contrary, the corresponding internal temperature $\theta_{0}$ was estimated at around $37.5 \pm 0.2^{\circ} \mathrm{C}$. Considering these two parameters, equation (7) becomes:

$$
\begin{aligned}
& {\left[\mathrm{Na}^{+}\right]=\left[\mathrm{Na}^{+}\right]_{0} \frac{\theta-\theta^{*}}{\theta_{0}-\theta^{*}}} \\
& \theta=\theta^{*}+\frac{\left[\mathrm{Na}^{+}\right]}{\left[\mathrm{Na}^{+}\right]_{0}}\left(\theta_{0}-\theta^{*}\right)
\end{aligned}
$$

Since the output voltage global sensitivity was found to depend on both sodium and chloride ions concentrations $\left[\mathrm{Na}^{+}\right]$and $\left[\mathrm{Cl}^{-}\right]$(cf. equation 1), the two parameters were studied independently using all different sweat samples (Fig. 11). Consequently, it appeared that they are linearly correlated [50]:

$$
\left[\mathrm{Cl}^{-}\right] \approx 0.92\left[\mathrm{Na}^{+}\right]
$$

Thus, according to equations (1) and (10), it can be written:

$$
\mathrm{V}_{\text {out }}=\mathrm{V}_{\text {cte }}+\mathrm{s}_{\mathrm{o}} \mathrm{pNa}
$$

with: $\mathrm{V}_{\text {cte }}=\mathrm{V}_{\text {offset }}-\mathrm{s}_{\mathrm{Ag} / \mathrm{agCl}} \log (0.92)$ and $\mathrm{s}_{0}=\mathrm{s}_{\mathrm{pNa} \text {-sensor }}+\mathrm{s}_{\mathrm{Ag} / \mathrm{AgCl}}$ 
As previously stated, by introducing the detection module output voltage $\mathrm{V}_{0}$ obtained for the very first sweat sample, equation (11) becomes:

$$
\mathrm{V}_{0}-\mathrm{V}_{\text {out }}=\Delta \mathrm{V}=\mathrm{s}_{0} \log \frac{\left[\mathrm{Na}^{+}\right]}{\left[\mathrm{Na}^{+}\right]_{0}}
$$

Finally, according to equations (9) and (12), the sodium ion concentration $\left[\mathrm{Na}^{+}\right]$in sweat and the internal temperature $\theta$ can be simply calculated:

$$
\left[\mathrm{Na}^{+}\right]=\left[\mathrm{Na}^{+}\right]_{0} 10^{\left(\frac{\Delta \mathrm{v}}{\mathrm{s}_{0}}\right)}
$$

or: $\theta=\theta^{*}+\left(\theta_{0}-\theta^{*}\right) 10^{\left(\frac{\Delta v}{\delta_{0}}\right)}$

where $\left[\mathrm{Na}^{+}\right]_{0}$ and $\theta_{0}$ are the sodium ion concentration and the internal temperature for the subject very first sweat sample respectively $\left(\left[\mathrm{Na}^{+}\right]_{0}\right.$ depends mainly on subject's physiology but $\theta_{0} \approx$ $\left.37.5^{\circ} \mathrm{C}\right), \mathrm{s}_{0}$ is the sodium sensor potentiometric sensitivity $\left(\mathrm{s}_{0} \approx 110 \mathrm{mV} /\right.$ decade $)$ and $\theta^{*}$ is a constant parameter $\left(\theta^{*} \approx 37.0^{\circ} \mathrm{C}\right)$.

Such equation system is very interesting since it makes simpler the sensor calibration procedure. Of course, in the frame of the natremia monitoring in sweat, the pNa sensor will have to be pre-calibrated previously in order to determine its analytical response. Thus, the very first sweat sample concentration $\left[\mathrm{Na}^{+}\right]_{0}$, which mainly depends on subject's physiology, will be estimated and the sweat $\left[\mathrm{Na}^{+}\right]$concentration will be finally monitored using equation (13). However, in the frame of the internal temperature $\theta$ monitoring, since the first sweat temperature $\theta_{0}$ can be considered as a constant parameter $\left(\theta_{0} \approx 37.5^{\circ} \mathrm{C}\right)$ for all subjects, the knowledge of the pNa-sensor global sensitivity $\mathrm{s}_{0}$ alone $(\sim 110 \mathrm{mV} /$ decade $)$ will be sufficient, with no need of any calibration. 
Thus, according to our experimental results and associated empirical studies, it can be concluded that (i) the natremia level in sweat is a good marker for the human heat stress analysis, (ii) potentiometric detection principles are well fitted to the measurement of the sodium ion concentration $\left[\mathrm{Na}^{+}\right]$in sweat, and (iii) $\mathrm{pNa}$-ISE and/or pNa-ISFET potentiometric results can be extended to internal temperature $\theta$ monitoring.

\subsection{In-vivo measurement}

In-vivo experiments were finally performed for ten subjects, during an ACHT test, using the physiological sweatband prototype with both pNa-sensor detection modules (Fig. 6). Half of them gave comprehensive results and, among them, the experiment of subject $\mathrm{n}^{\circ} 7$ was finally chosen for discussion. In such real conditions, both detection modules gave similar voltage variations, allowing us to study them globally (result not shown). Then, using the previous pNa-ISE and pNaISFET calibrations (equations 3 and 4 respectively), we were able to measure in real time the sodium ion concentration $\left[\mathrm{Na}^{+}\right]$in sweat (Fig. 12). It takes roughly a quarter of an hour after the beginning of the test to obtain a first comprehensive answer. As shown previously (cf. section 3.2), this delay should be associated to the time required for sweating phenomena to start (10-15 minutes) and for the textile-based pump to transport sweat towards the sensor sensitive surface $(\sim 2$ minutes). Then, the sodium concentration in sweat was monitored continuously. Thus, in agreement with standard chemical analysis (Roche Hitachi 912 chemistry analyzer) performed on samples collected from sweat pockets, a similar trend was obtained for both detection modules, demonstrating a $\left[\mathrm{Na}^{+}\right]$global increase during the ACHT test.

The use of integrated sensors for the sweat natremia monitoring during physical exercise was already shown in literature. S. Coyle et al. developed a "pNa-ISE - gold reference electrode" sweat patch and were able to demonstrate the pNa-ISE open circuit potential $(\mathrm{OCP})$ increase with time, assuming the correlation with the sweat $\left[\mathrm{Na}^{+}\right]$concentration [44]. B. Schazmann et al. developed a 
"pNa-ISE - Ag/AgCl/KCl reference electrode" sweat sensor belt (sensitivity: $50 \mathrm{mV} / \mathrm{pNa}$ ) and were able to monitor effectively the sweat $\left[\mathrm{Na}^{+}\right]$concentration increase with exercise trial duration [45]. Nevertheless, due to the use of a non-integrated solid/liquid reference electrode, this microsensor was finally not fully compatible with standard sweatbands. Finally, A. Bandodkar et al. developed "pNa-ISE - Ag/AgCl reference electrode" epidermal tattoos (detection sensitivity: $\sim 64 \mathrm{mV} / \mathrm{pNa}$ ) for sweat analysis [43]. Thus, they were able to monitor the skin/sweat natremia before and after perspiration, always demonstrating a final $\left[\mathrm{Na}^{+}\right]$concentration increase with time. Compared to our results, these improved performances should be associated to a more functional integration of the potentiometric detection system. Nevertheless, such tattoo-like technology can be qualified as temporary and its capacity to handle high sweat production rates and volumes for longterm skin analysis was not fully demonstrated. Compared to these works, the proposed technology, either based on ISE or ISFET sensors (global detection sensitivity: $110 \mathrm{mV} / \mathrm{pNa}$ ), is fully compatible with standard sweatbands and confirmed the sweat $\left[\mathrm{Na}^{+}\right]$concentration increase with time during an exercise trial. Moreover, its main achievement should also be associated to the monitoring of physiological hyperthermia. Indeed, considering the initial temperature $\theta_{0}$ associated to the first sweat sample $\left(\theta_{0}=37.5^{\circ} \mathrm{C}\right)$ and according to equation (14), we were also able to determine the internal temperature variations during the ACHT test, evidencing a global increase in agreement with rectal temperature measurements (Fig. 13). Such result demonstrates that the indirect internal temperature measurement technique based on sweat natremia analysis has similar performances to the rectal probe (known as the best one). Of course, it will be argued that measurement accuracy will have to be more precisely calculated. According to physiological discrepancy between subjects, it could be estimated to $\pm 0.2^{\circ} \mathrm{C}$ (compared to $0.05^{\circ} \mathrm{C}$ for the rectal or tympanic probe). Such measurement accuracy should be sufficient for physiological applications. Moreover, even if rectal and tympanic probes were used in our sweating tests (SWT, HTCP and HTCA), their use for physiological monitoring in real life is not conceivable for obvious reasons. 
All in all, these experiments allow a better understanding of human sweating phenomenon during a mixed internal and external heat-load. Starting at neutral internal temperature $(37.0 \pm$ $0.2^{\circ} \mathrm{C}$ ), muscular activity is responsible for a physiological heat production and therefore an internal temperature increase. However, no sweating occurs up to $37.5 \pm 0.2^{\circ} \mathrm{C}$. As soon as the internal temperature reaches this threshold value, sweating is triggered in order to dissipate heat due to sweat evaporation. In the case of a sweating test (SWT), thermoregulation is efficient to maintain (or even decrease) the internal temperature $\theta$ as well as the sodium concentration $\left[\mathrm{Na}^{+}\right]$constant. In the case of an ACHT test, wearing of a CBRN protection suit prevents evaporation of sweat and therefore any thermal regulation. As a result, the internal temperature $\theta$ as well as the sweat sodium concentration $\left[\mathrm{Na}^{+}\right]$increase gradually in a correlated way.

\section{Conclusion}

Two technologies, based on pNa-ISE and pNa-ISFET potentiometric devices, were developed and compared for the in-vivo monitoring of natremia in sweat. In order to do so, they were integrated in a physiological sweatband prototype incorporating a textile-based sweat pump to collect sweat in real time. Characterized by similar $\mathrm{Na}^{+}$ion global detection sensitivities, i.e. 110 $\mathrm{mV} / \mathrm{pNa}$ due to the use of an integrated "Ag/AgCl-ink" pseudo-reference electrode, both $\mathrm{pNa}$ microsensors enabled to determine in real time the $\left[\mathrm{Na}^{+}\right]$concentration in sweat, demonstrating a global increase during hard physical exercises.

Finally, potentiometry was found to be well-fitted with human physiology. Indeed, according to an experimental campaign on twenty-five healthy consenting subjects, $\left[\mathrm{Na}^{+}\right]$concentration in sweat was linearly related to the corresponding $\left[\mathrm{Cl}^{-}\right]$concentration as well as to subject's internal temperature $\theta$. Thus, through the analysis of the first sweat sample, the use of pNa potentiometric microsensors (ISE and/or ISFET) allowed to monitor the sweat natremia as well as the internal temperature, independently of the subject physiology and without any complex calibration 
procedure. All in all, the relevance of the $\mathrm{Na}^{+}$ion analysis was therefore demonstrated for the physiological stress analysis.

Lastly, coming back to our core interest, i.e. the safety of first responders (soldiers, fire fighters,...) in their everyday rescue actions, the developed pNa-sensitive sweatband is finally fully compatible with others already-worn for heart rate monitoring. Thus, through sweat natremia analysis and associated internal temperature measurement, it could be used to prevent hyperthermia and related physiological threats. Furthermore, potentiometric detection could be applied to the detection of other chemical and/or biochemical species in sweat, still improving physiological diagnosis and associated safety. Finally, in a less lethal context, developments can be extended to physiological monitoring in the frame of sport practice.

\section{Acknowledgements}

The project was financially supported by the French "Agence Nationale de la Recherche" (ANR CSOSG, SWEAT project, nANR-08-SECU-010) in partnership with the French "Direction de la Police Nationale (DPN)" and "Direction Générale de l'Armement (DGA)". The authors would like to thank Y. Besnard, N. Clerc, C. Bourrilhon, J. Denis, P. Colin, J. Bompard and A. Alonso from IRBA-CRSSA for in-vivo physiological measurements and associated analysis. Finally, technological realizations were partly supported by the French RENATECH network.

\section{References}

[1] K. Parsons, "Human thermal environment: the effects of hot, moderate and cold environments on human health, comfort and performance", $2^{\text {nd }}$ edition", Taylor and Francis, London, England (2003), ISBN: 0-415-23793-9 
[2] S. Robinson and H. Robinson, "Chemical composition of sweat", Physiological Reviews, 34 (1954) 202-220

[3] E.F. Adolph and associates, "Physiology of man in the desert", New-York: Intersciences (1947)

[4] M.N. Sawka and S.J. Montain, "Fluid and electrolyte supplementation for exercise heat stress", American Journal of Clinical Nutrition, 72 (2000) 564s-572s

[5] S.M. Shirreffs, L.F. Aragon-Vargas, M. Chamorro, R.J. Maughan, L. Serratosa and J.J. Zachwieja, "The sweating response of elite professional soccer players to training in the heat", International Journal of Sports Medicine, 26 (2005) 90-95

[6] E.H. Fisberg and W. Bierman, "Acid-base balance in sweat", Journal of Biological Chemistry, 97 (1932) 443-441

[7] O. Mickelsen and A. Keys, "The composition of sweat with special reference to the vitamins", Journal of Biological Chemistry, 149 (1947) 479-490

[8] D.L. Costill, "Sweating: its composition and effects on body fluids", Annals of the New-York Academy of Science, 301 (1977) 160-174

[9] D. Czarnowki and J. Gorski, "Sweat ammonia excretion during submaximal cycling exercise", Journal of Applied Physiology, 70 (1991) 371-374

[10] W.A. Latzka and S.J. Montain, "Water and electrolyte requirements for exercise", Clinics in Sports Medicine, 18 (1999) 513-524

[11] C.T. Huang, M.L. Chen, L.L. Huang and I.F. Mao, "Uric acid and urea in human sweat", Chinese Journal of Physiology, 45 (2002) 109-115

[12] M. Saat, Y. Tochihara, N. Haschiguchi, R.G. Sirinsinghe, M. Fujita and C.M. Chou, "Effects of exercise in the heat of thermoregulation of Japanese and Malaysian males", Journal of Physiology and Anthropology Applied to Human Sciences, 24 (2005) 267-275

[13] F. Meyer, O. Laitano, O. Bar-Or, D. McDougall and G.J. Heigenhauser, "Effect of age and gender on sweat lactate and ammonia concentrations during exercise in the heat", Brazilian Journal of Medical and Biological Research, 40 (2007) 135-143 
[14] R.J. Maughan, "Fluid and electrolyte loss and replacement in exercise", Journal of Sports Sciences, 9 (1991) 117-142

[15] S.M. Shirreffs and R.J. Maughan, "Whole body sweat collection in humans: an improved method with preliminary data on electrolyte content", Journal of Applied Physiology, 82 (1997) $336-341$

[16] S.J. Montain, S.N. Cheuvront and H.C. Lukaski, "Sweat mineral-element responses during 7h of exercise heat stress", International Journal of Sport Nutrition and exercise metabolism, 17 (2007) 574-582

[17] A.K.M. Shamsuddin, S. Yanagimoto, T. Kuwahara, Y. Zhang, C. Nomura and N. Kondo, "Changes in the index of sweat ion concentration with increasing sweat during passive heat stress in humans", European Journal of Applied Physiology, 94 (2005) 292-297

[18] Z.M. Baccar, N. Jaffrezic-Renault, C. Martelet, H. Jaffrezic, G. Marest and A. Plantier, "Sodium microsensors based on ISFET/REFET prepared through an ion implantation process fully compatible with a standard silicon technology", Sensors and Actuators B, 32 (1996) 101105

[19] P.K. Shin and T. Mikolajick, " $\mathrm{H}^{+}, \mathrm{Na}^{+}$and $\mathrm{K}^{+}$ion sensing properties of sodium and aluminium co-implanted LPCVD silicon oxynitride thin films", Applied Surface Science, 207 (2003) 351358

[20] U. Oesch, D. Amman and W. Simon, "Ion-selective membrane electrodes for clinical use", Clinical Chemistry, 32/8 (1986) 1448-1459

[21] N. Abramova and A. Bratov, "Photocurable polymers for ion selective field effect transistors. 20 Years of Applications", Sensors, 9 (2009) 7097-7110

[22] U. Oesch, S. Caras and J. Janata, "Field effect transistors sensitive to sodium and ammonium ions", Analytical Chemistry, 53 (1981) 1983-1986 
[23] J.A.J. Brunink, J.R. Haak, J.G. Bomer and D. Reinhoudt, "Chemically modified field effect transistors; a sodium ion selective sensor based on calix[4]arene receptor molecules", Analytica Chimica Acta, 254 (1991) 75-80

[24] Y. Tsujimura, M. Yokohama and K. Kimura, "Comparison between silicone rubber membranes and plasticized poly(vinyl chloride) membranes containing calix[4]arene ionophores for sodium-selective field-effect transistors in applicability to sodium assay in human body fluids", Sensors and Actuators B., 22 (1994) 195-199

[25] D.G. Pijanowska, E. Luboch, J.F. Biernat, M. Dawgul and W. Torbicz, "Na ${ }^{+}$-selective ChemFETs based on a novel ionophore: bis(phenylbenzo)-13-azocrown-5", Sensors and Actuators B, 58 (1999) 384-388

[26] M. Chudy, W. Wroblewski, A. Dybko and Z. Brzozka, "Multi-ion analysis based on versatile sensor head", Sensors and Actuators, B78 (2001) 320-325

[27] J. Muñoz, C. Jimenez, A. Bratov, J. Bartroli, S. Alegret and C. Dominguez, "Photosensitive polyurethanes applied to the development of ChemFET and EnFET devices for biomedical sensing", Biosensors and Bioelectronics, 12 (1997) 577-585

[28] A. Ipatov, N. Abramova, A. Bratov and C. Dominguez, "Integrated multisensor chip with sequential injection technique as a base for "electronic tongue" devices", Sensors and Actuators $B, 131(2008) 48-52$

[29] I.A. Marques de Oliveira, D. Risco, F. Vocanson, E. Crespo, F. Teixidor, N. Zine, J. Bausells, J. Samitier and A. Errachid, "Sodium ion sensitive microelectrode based on a p-tertbutylcalix[4]arene ethyl ester", Sensors and Actuators B, 130 (2008) 295-299

[30] S.J. Harris, "Chemically modified field effect transistors; a sodium ion selective sensor based on calix[4]arene receptor molecules", Analytica Chimica Acta, 254 (1991) 75-80

[31] J.A.J. Brunink, "The design of durable $\mathrm{Na}^{+}$selective ChemFETs based on polysiloxane membranes", Journal of Electroanalytical Chemistry, 378 (1994) 185-200 
[32] R.N. Reinhoudt, "Durable chemical sensors based on field-effect transistors", Sens. Actuators B: Chem. 24-25 (1995) 197-200

[33] G. Högg, O. Lutze and K. Camman, "Novel membrane material for ion-selective field-effect transistors with extended lifetime and improved selectivity", Analytica Chimica Acta, 335 (1996) 103-109

[34] C. Dumschat, S. Alazard, S. Adam, M. Knoll and K. Camman, "Filled fluorosiloxane as matrix for ion-selective membranes", Analyst, 121 (1996) 527-529

[35] A. Cazalé, W. Sant, J. Launay, F. Ginot and P. Temple-Boyer, "Study of field effect transistors for the sodium ion detection using fluoropolysiloxane-based sensitive layers", Sensors and Actuators, B177 (2013) 515-521

[36] A. Bandodkar and J. Wang, "Non-invasive wearable electrochemical sensors: a review", Trends in Biotechnology, 32 (2014) 363-371

[37] C. Christophe, F. Sékli Belaïdi, J. Launay, P. Gros, E. Questel and P. Temple-Boyer, "Elaboration of integrated microelectrodes for the detection of antioxidant species", Sensors and Actuators, B177 (2013) 350-356

[38] M. Gamella, S. Campuzano, J. Manso, G. Gonzalez de Rivera, F. Lopez-Colino, A.J. Reviejo and J.M. Pingarron, "A novel non-invasive electrochemical biosensing device for in situ determination of the alcohol content in blood by monitoring ethanol in sweat", Analytica Chimica Acta, 806 (2014) 1-7

[39] X.H. Huang, Y. Liu, K. Chen, W.J. Shin, C.J. Lu, G.W. Kong, D. Patnaik, S.H. Lee, J. Fajardo Cortez and J.A. Rodgers, "Stretchable, wireless sensors and functional substrates for epidermal characterization of sweat", Small, 10 (2014) 3083-3090

[40] J.R. Windmiller, A.J. Bandodkar, G. Valdés-Ramirez, S. Parkhomovsky, A.G. Martinez and J. Wang, "Electrochemical sensing on printable temporary transfer tattoos", Chemical Communications, 48 (2012) 6794-6796 
[41] W. Jia, A.J. Bandodkar, G. Valdés-Ramirez, J.R. Windmiller, Z. Yang, J. Ramirez, G. Chan and J. Wang, "Electrochemical tattoo biosensors for real-time non-invasive lactate monitoring in human perspiration", Analytical Chemistry, 85 (2013) 6553-6560

[42] A.J. Bandodkar, V.W.S. Hung, W. Jia, G. Valdés-Ramirez, J.R. Windmiller, A.G. Martinez, J. Ramirez, G. Chan, K. German and J. Wang, "Tattoo-based potentiometric ion-selective sensors for epidermal pH monitoring", Analyst, 138 (2013) 123-128

[43] A.J. Bandodkar, D. Molinnus, O. Mirza, T. Guinovart, J.R. Windmiller, G. Valdés-Ramirez, F.J. Andrade, M.J. Schöning and J. Wang, "Epidermal tattoo potentiometric sodium sensors with wireless signal transduction for continuous non-invasive sweat monitoring", Biosensors and Bioelectronics, 54 (2014) 603-609

[44] S. Coyle, K.T. Lau, N. Moyna, D. O'Gorman, D. Diamond, F. Di Francesco, D. Costanzo, P. Salvo, M.G. Trivella, D.E. De Rossi, N. Taccini, R. Paradiso, J.A. Porchet, A. Rifoldi, J. Luprano, C. Chuzel, T. Lanier, F. Revol-Cavalier, S. Schoumacker, V. Mourier, I. Chartier, R. Convert, H. De-Montcuit and C. Bini, "BIOTEX - Biosensing textiles for personalised healthcare management", IEEE transactions on Information Technology in Biomedecine, 14 (2010) 364-370

[45] B. Schazmann, D. Morris, C. Slater, S. Beirne, C. Fay, R. Reuveny, N. Moyna and D. Diamond, "A wearable electrochemical sensor for the real-time measurement of sweat sodium concentration", Analytical Methods, 2 (2010) 342-348

[46] W. Sant, P. Temple-Boyer, E. Chanié, J. Launay and A. Martinez, "On-line monitoring of urea using enzymatic field effect transistors", Sensors and Actuators B, B160 (2011) 59-64

[47] J.C. Launay, Y. Besnard, I. Sendowski, A. Guinet, A.M. Hanniquet and G. Savourey, "Anthropological and thermoregulatory changes induced by a survical sojourn in a tropical climate", Wilderness Environmental Medecine, 13 (2002) 5-11

[48] G.R. Brisson, P. Boisvert, F. Péronnet, H. Perrault, D. Boisvert and J.S. Lafond, "A simple and disposable sweat collector", European Journal of Applied Physiology and Occupational 
Physiology, 63 (1991) 269-272, erratum in: European Journal of Applied Physiology, 66 (1193) 552

[49] N.A.S. Taylor and C.A. Machado-Moreira, "Regional variations in transepidermal water loss, eccrine sweat gland density, sweat secretion rates and electrolyte composition in resting and exercising humans", Extreme Physiology and Medicine, 2 (2013) 1-29

[50] K. Sato, W.H. Kang, K. Saga and K.T. Sato, "Biology of sweat glands and their disorders, I: normal sweat gland function", Journal of the American Academy of Dermatology, 20 (1989) $537-563$

\section{Biographies}

Arnaud Cazalé was born on November 1985. He received his Master's Degree in electronics embedded micro-systems from University "Paul Sabatier de Toulouse" (France) in 2009. He joined HEMODIA company (France) in the same time and started research works in collaboration with the French "Laboratoire d'Analyse et d'Architecture des Systèmes" of the French "Centre National de la Recherche Scientifique" (LAAS-CNRS) to develop sodium sensitive ChemFET microsensors for medical applications. He received the PhD degree from University "Paul Sabatier de Toulouse" (France) in 2013. Since then, he has joined the NANOMADE company (France) as an R\&D engineer and has been working on the development of stress sensors for smart screen applications.

William Sant was born on May 1969. He received his Master's Degree in Electronics in 1996 and his "Diplome d'Etudes Approfondies" in Microelectronics in 1999, both from University "Paul Sabatier de Toulouse" (France). He joined the French "Laboratoire d'Analyse et d'Architecture des Systèmes" of the French "Centre National de la Recherche Scientifique" (LAAS-CNRS) in 2000 and received the $\mathrm{PhD}$ degree from University "Paul Sabatier de Toulouse" (France) in 2004. Since 
then, he has joined the HEMODIA company (France) as an R\&D engineer and has been working on the development of ChemFET microsensors for medical applications.

Frédéric Ginot was born on September 1962. He received his Engineer Master's Degree from the French "Ecole Polytechnique" (Paris - France) in 1985 and a $\mathrm{PhD}$ in molecular biology from Paris University VII in 1989. After various jobs in $R \& D$, at the interface between engineering and biosciences, he joined HEMODIA/CAPTOMED company as vice-president for Research \& Development in 2010.

Jean-Claude Launay was born on April 1961, received his doctorate in medicine in 1988 from Claude Bernard University in Lyon (France), his $\mathrm{PhD}$ in physiology of extreme environments and his French "Habilitation à diriger des recherches" at the University of Lyon in 2008. He joined the French "Unité de thermophysiologie" then "Pôle tolérance climatique et vêtements" of the French "Centre de recherches du service de santé des armées" (CRSSA) in 1995, before taking the direction of the "Unité Environnements extrêmes" of the Institute of biomedical researches of the French Army (IRBA-CRSSA) for four years. During all these years, he studied human physiological tolerance and adaptation to heat, cold, altitude and protective clothing. Since then, after 18 years in biomedical research on tolerance of man in extreme environments (mainly in heat, cold and altitude and also on protective clothing) he has been working as an occupational practitioner at STMicroelecronics company (Crolles -France).

Gustave Savourey was born on February 1956. Medicine doctor in 1981, he received his PhD degree in "Biology of physical exercise" in 1987 from Claude Bernard University in Lyon (France) and his French "Habilitation à diriger des recherches" at the University of Lyon in 1993. He joined the French "Unité de thermophysiologie" of the French "Centre de recherches du service de santé des armées" (CRSSA) in 1986 and became its head director in 1997, studying the physiological 
responses of humans submitted to climatic constraints, especially heat, cold, terrestrial altitudes and protective clothing. In 2009, he directed the French "Pôle Facteurs Humains" of the Institute of biomedical researches of the French Army (IRBA - CRSSA) and is retired since 2013.

Frederic Revol-Cavalier was born on September 1963. He received his Engineer Degree in Materials and Electrochemistry from the Institute National Polytechnic of Grenoble in 1995. He joined the French "Laboratoire d'Electronique et des Technologies d'Instrumentations" of the French "Commissariat à l'Energie Atomique et aux Energies Alternatives" in 1991 as an engineer in cleanroom laboratories. Since 1995, he has been working on the development of sensors for biological and health for wellness applications.

Jean-Michel Lagarde was born on February 1966. He received his Engineer Degree in physics from the National School of Physics of Marseille (France), option "Image Processing" in 1990. After two years in a contract research organization at the Institute for research on skin function tests in Marseille (France), he joined the "Pierre Fabre" laboratories in Toulouse (France) as chief project for "Fundamental biometrology". In 1998, he took the direction of the division "Engineering and imaging of the skin". Finally, he funded Pixience society in 2012 and is currently the chief technology officer of this start-up.

Didier Heinry was born on December 1963. He received his Master's Degree in 1987 and his French "Diplome d'Etudes Approfondies" in 1988, both from the French "Université de Perpignan" (France). He joined the French "Ingénierie des Matériaux et génie des Procédés" (IMP) laboratory and received the $\mathrm{PhD}$ degree in "Energetic Systems" from the French "Université de Perpignan" in 1992. Since then, he has joined the "PAUL BOYE Technologies" company (France) as an R\&D engineer and finally as an R\&D chief project and has been working on the development of smart protection clothes and combat wears. 
Jérôme Launay was born on March 1975. He received the degree in electronic engineering from the French "Institut National des Sciences Appliquées de Toulouse" (INSAT-France) in 1998. He joined the French "Laboratoire d'Analyse et d'Architecture des Systèmes" from the French "Centre National de la Recherche Scientifique" (LAAS-CNRS) in 1998 and received the PhD degree from the French "Institut National des Sciences Appliquées de Toulouse" (INSAT-France) in 2001. In 2002, he became lecturer at University "Paul Sabatier de Toulouse" (France). His research activities include the development of chemical microsensors for the detection in liquid phase.

Pierre Temple-Boyer was born on October 1966. He received his Engineer Degree in electronic engineering from the French "Ecole Supérieure d'Electricité" (Paris - France) in 1990 and his Master Degree in microelectronics from University "Paul Sabatier de Toulouse" (France) in 1992. He joined the french "Laboratoire d'Analyse et d'Architecture des Systèmes" of the French "Centre National de la Recherche Scientifique" (LAAS-CNRS) in 1992 and received the PhD degree from the French "Institut National des Sciences Appliquées de Toulouse" (INSAT - France) in 1995. Since then, as a senior researcher, he has been working on the development of micro- and nanotechnologies. 


\section{Tables and figures caption}

Table 1: biometrical characteristics of the twenty-five male subjects participating in the sweating tests ( $\mathrm{V}_{2} \max$ : maximal oxygen consumption)

Fig. 1: Fabrication scheme of the pNa-ISE detection module: a) gluing PVC platform on electronic circuit, b) filling solution into the cavity, c) drop-casting of the $\mathrm{Na}^{+}$-sensitive PVC solution,

d) formation of the $\mathrm{Na}^{+}$-sensitive sealing PVC membrane

Fig. 2: Details of the pNa-ISE detection module integrating into a PVC platform three measurement electrodes (ET1, ET2, ET3) covered by a $\mathrm{Na}^{+}$-sensitive PVC membrane

Fig. 3: Details of the ISFET detection module integrating a pNa-ISFET, a pH-ChemFET and an "Ag/AgCl" ink pseudo-reference electrode

Fig. 4: Integration of both pNa-ISE and pNa-ISFET detection modules as well as associated electronic measurement interfaces on a flexible substrate

Fig. 5: Development of a textile-based sweat pump

Fig. 6: Development of a physiological sweatband prototype involving the pNa-ISE and pNaISFET detection modules, the associated electronic interfaces and the textile-based sweat pump, application to the monitoring of human sweating phenomena

Fig. 7: Analytical response of the pNa-ISE detection module 
Fig. 8: Analytical response of the pNa-ISFET detection module

Fig. 9: Relation between the sweat sodium ion concentration $\left[\mathrm{Na}^{+}\right]$and the internal temperature $\theta$ for different subjects while considering SWT, PCHT and ACHT tests (measurement accuracy: $\pm 0.02 \mathrm{pNa}$ and $\pm 0.05^{\circ} \mathrm{C}$ )

Fig. 10: Relation between (-b) and a parameters for all subjects

Fig. 11: Relation between the $\left[\mathrm{Cl}^{-}\right]$and $\left[\mathrm{Na}^{+}\right]$concentrations in sweat for all subjects (measurement accuracy: $\pm 0.02 \mathrm{pCl}$ and $\mathrm{pNa}$ )

Fig. 12: Monitoring of the sodium concentration $\left[\mathrm{Na}^{+}\right]$in sweat during an ACHT test, comparison of pNa-ISE and pNa-ISFET detection modules with standard chemical analyses (measurement accuracy: $\pm 0.02 \mathrm{pNa}$ )

Fig. 13: Study of the internal temperature variations during an ACHT test, comparison with standard rectal measurements (measurement accuracy: $\pm 0.05^{\circ} \mathrm{C}$ ) 


\begin{tabular}{|c|c|c|c|c|c|}
\hline & $\begin{array}{c}\text { Body mass } \\
(\mathrm{kg})\end{array}$ & $\begin{array}{c}\text { Height } \\
(\mathrm{m})\end{array}$ & $\begin{array}{c}\text { Body area } \\
\left(\mathrm{m}^{2}\right)\end{array}$ & $\begin{array}{c}\text { Body fat } \\
\text { mass }(\%)\end{array}$ & $\begin{array}{c}\mathrm{VO}_{2} \max \\
(\mathrm{mL} / \mathrm{min} . \mathrm{kg})\end{array}$ \\
\hline mean & 74.93 & 1.78 & 1.92 & 16.4 & 51.5 \\
\hline standard deviation & 8.49 & 0.06 & 0.13 & 2.8 & 7.4 \\
\hline minimum & 56.29 & 1.64 & 1.65 & 25.6 & 38.0 \\
\hline maximum & 87.65 & 1.90 & 2.15 & 12.8 & 65.2 \\
\hline
\end{tabular}

Table 1: biometrical characteristics of the twenty-five male subjects participating in the sweating tests ( $\dot{\mathrm{VO}}_{2}$ max: maximal oxygen consumption) 
a)

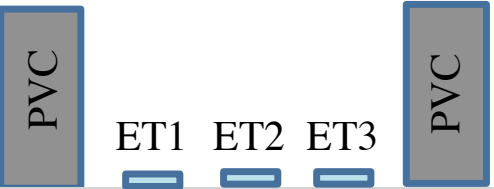

c)

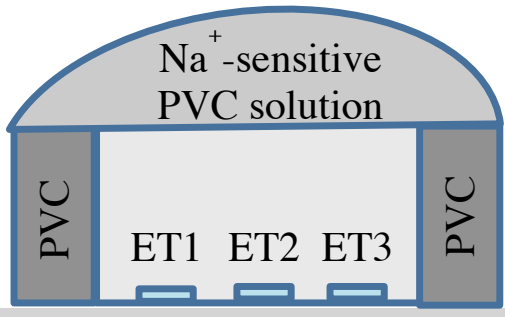

Fig. 1: Fabrication scheme of the pNa-ISE detection module: a) gluing PVC platform on electronic circuit, b) filling solution into the cavity, c) drop-casting of the $\mathrm{Na}^{+}$-sensitive PVC solution,

d) formation of the $\mathrm{Na}^{+}$-sensitive sealing PVC membrane 


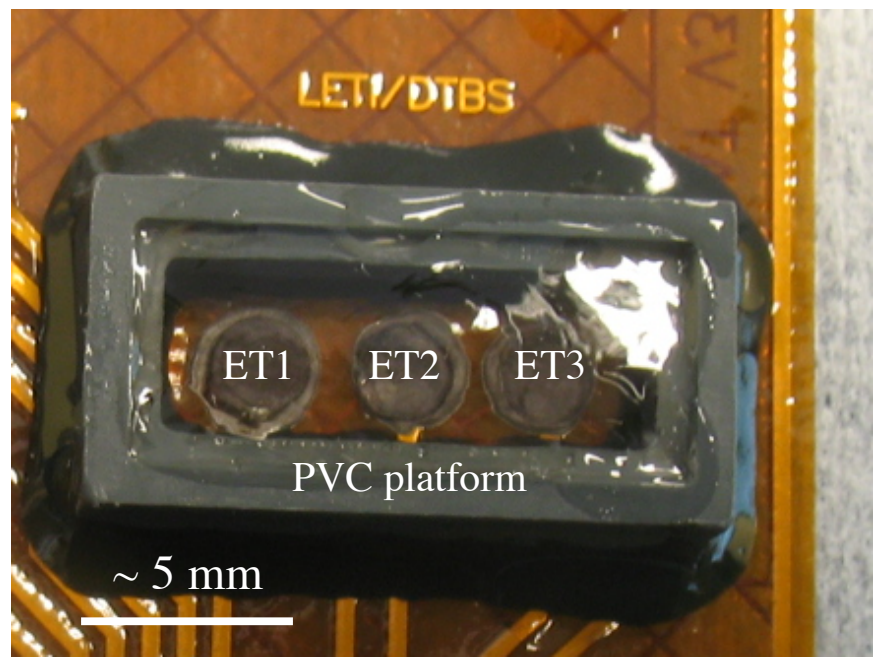

Fig. 2: Details of the pNa-ISE detection module integrating into a PVC platform three measurement electrodes (ET1, ET2, ET3) covered by a $\mathrm{Na}^{+}$-sensitive PVC membrane 


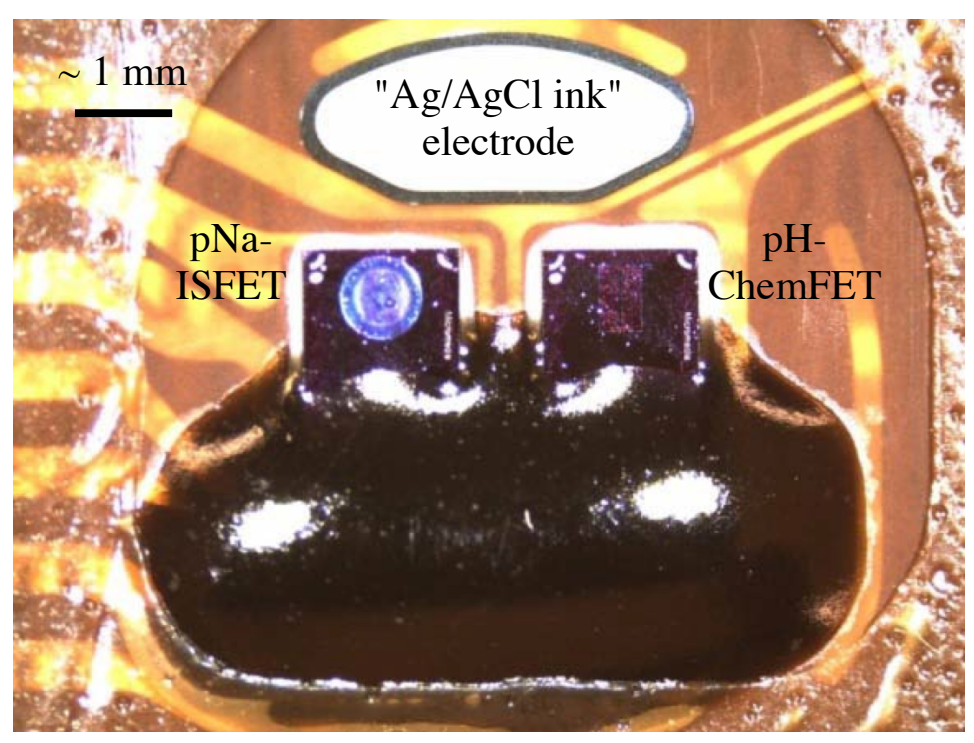

Fig. 3: Details of the ISFET detection module integrating a pNa-ISFET, a pH-ChemFET and an "Ag/AgCl ink" pseudo-reference electrode 


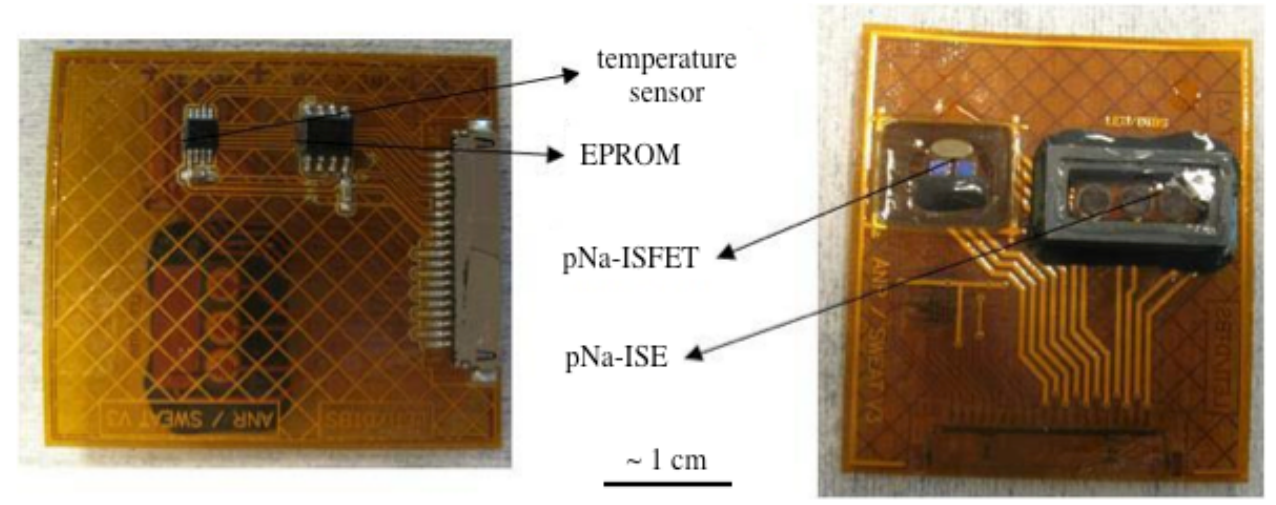

Fig. 4: Integration of both pNa-ISE and pNa-ISFET detection modules

as well as associated electronic measurement interfaces on a flexible substrate 
flexible substrate with

$\mathrm{pNa}$ detection modules

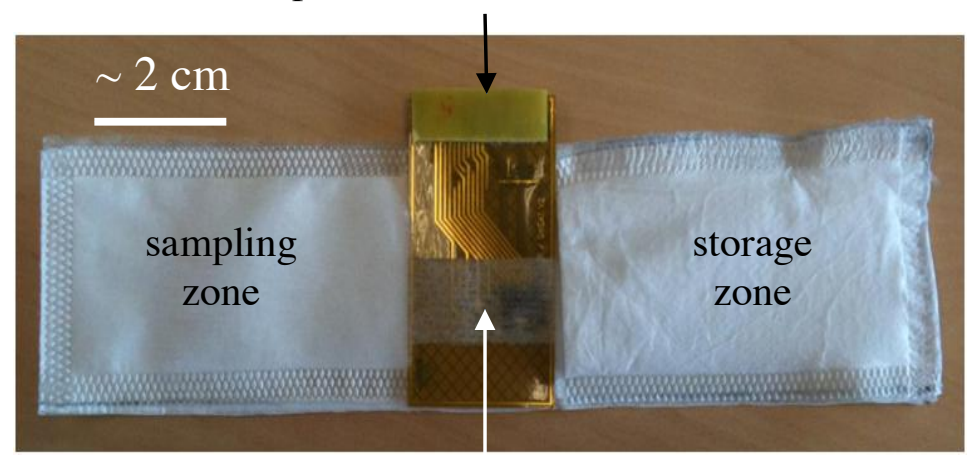

transfer zone

Fig. 5: Development of a textile-based sweat pump 


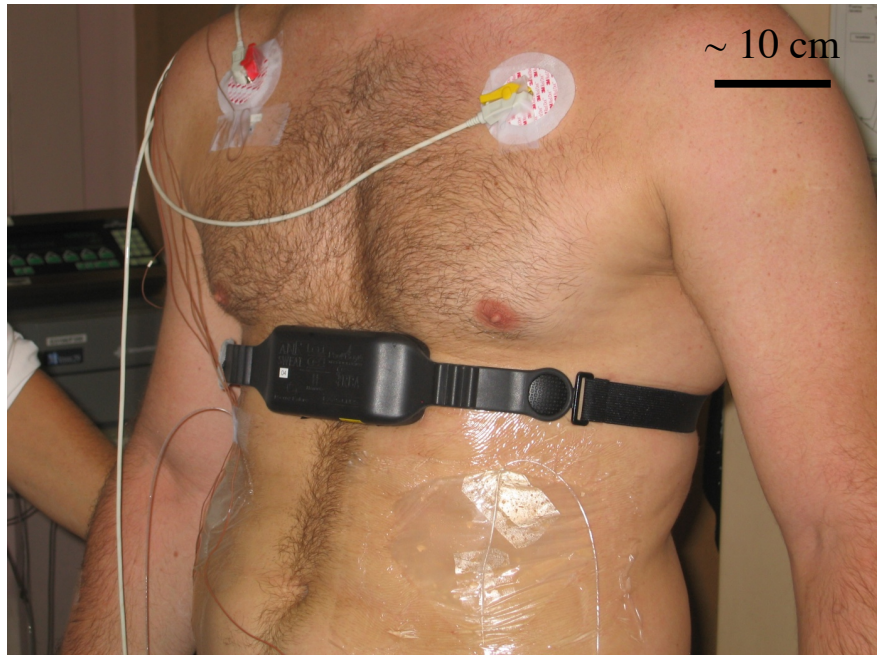

Fig. 6: Development of a physiological sweatband prototype involving the pNa-ISE and pNaISFET detection modules, the associated electronic interfaces and the textile-based sweat pump, application to the monitoring of human sweating phenomena 


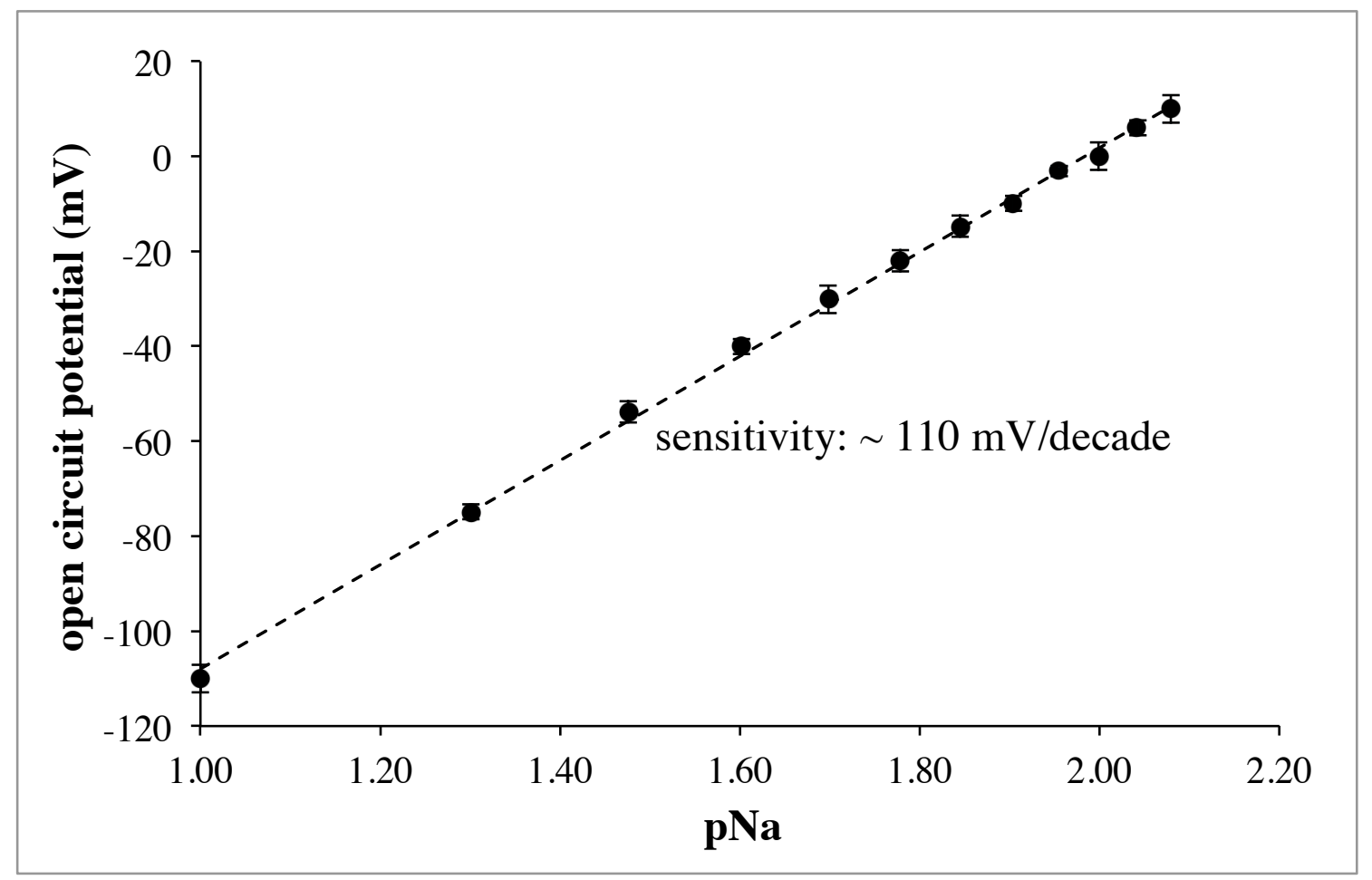

Fig. 7: Analytical response of the pNa-ISE detection module 


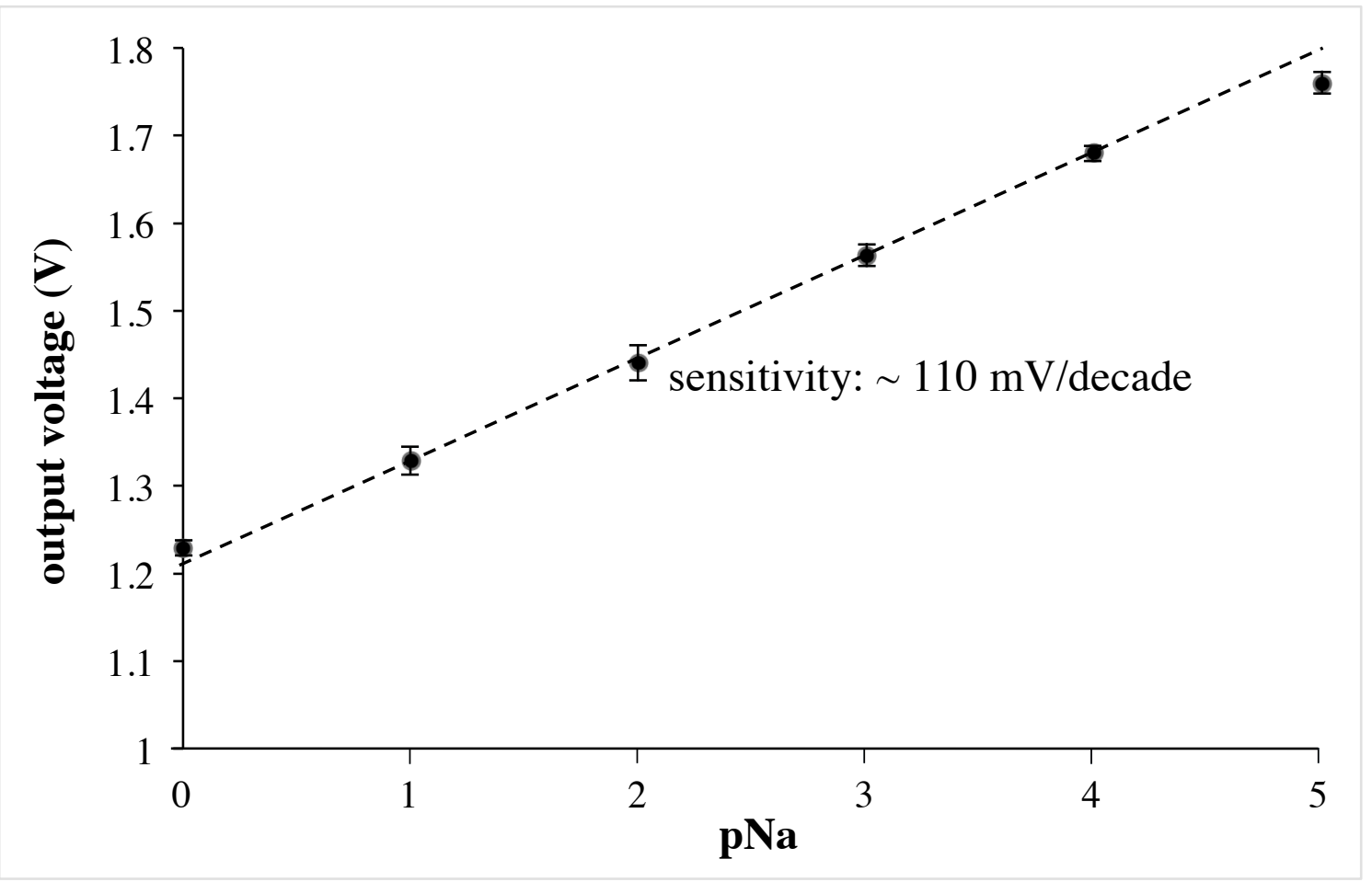

Fig. 8: Analytical response of the pNa-ISFET detection module 


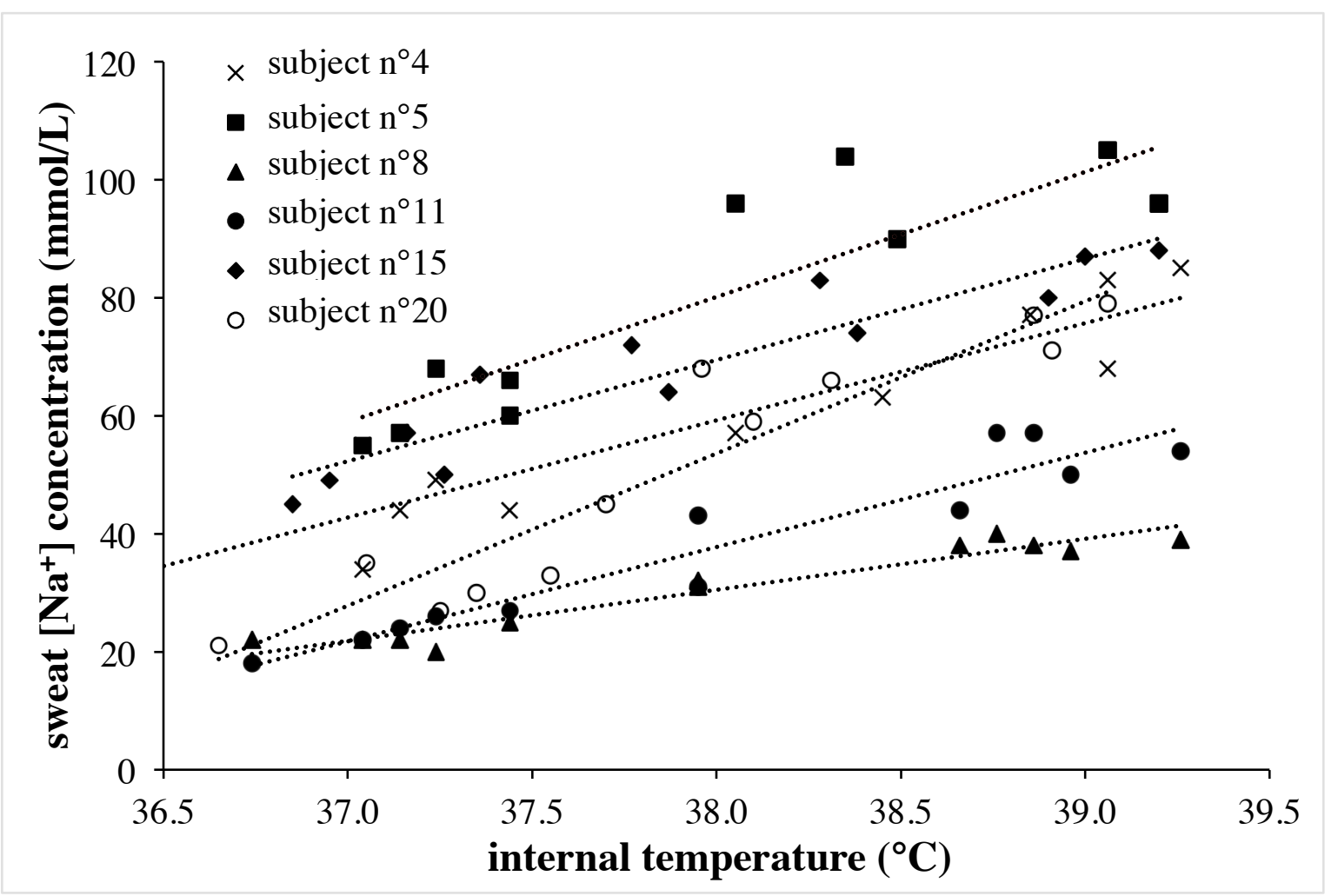

Fig. 9: Relation between the sweat sodium ion concentration $\left[\mathrm{Na}^{+}\right]$and the internal temperature $\theta$ for different subjects while considering SWT, PCHT and ACHT tests (measurement accuracy: $\pm 0.02 \mathrm{pNa}$ and $\pm 0.05^{\circ} \mathrm{C}$ ) 


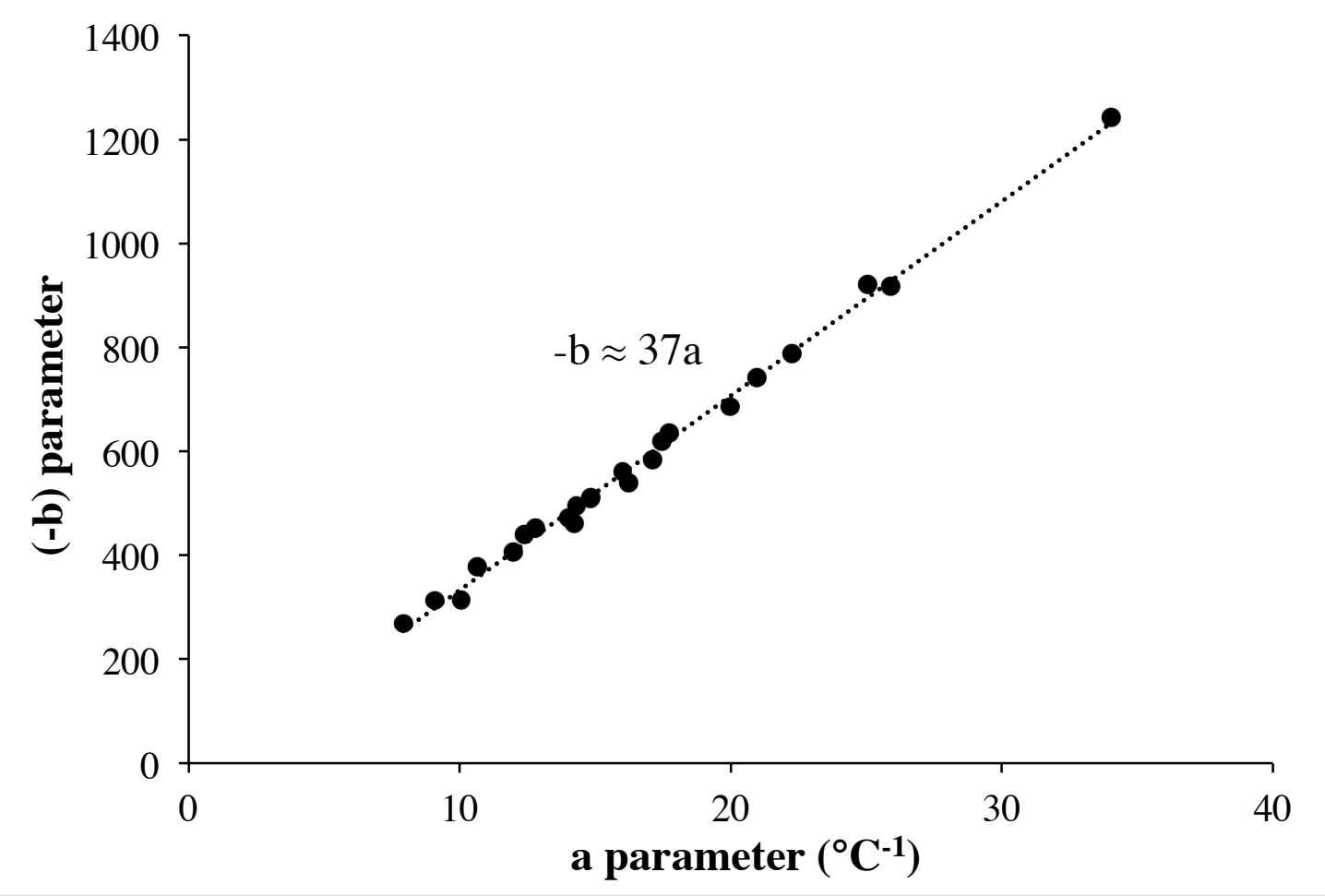

Fig. 10: Relation between (-b) and a parameters for all subjects 


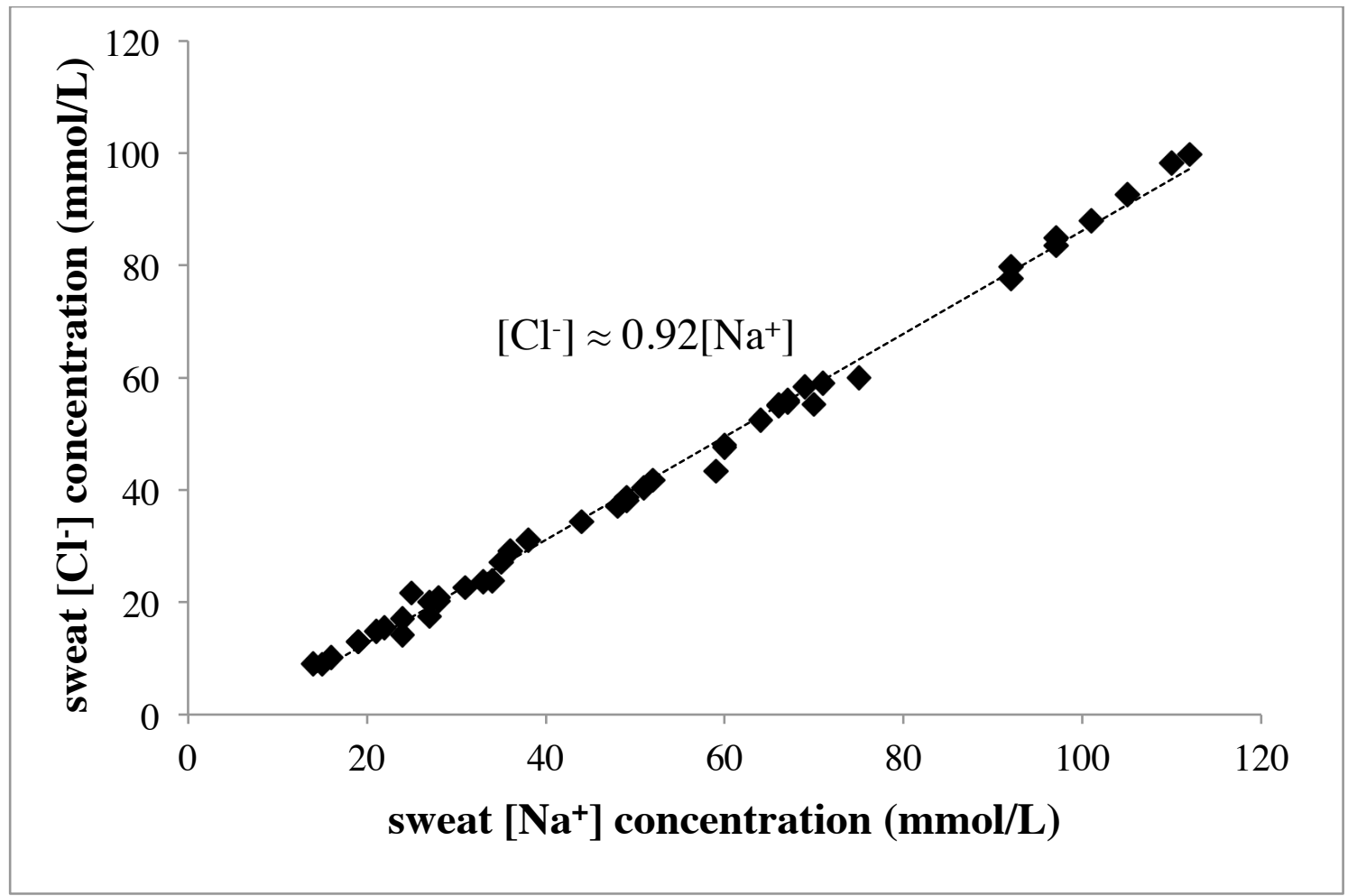

Fig. 11: Relation between the $\left[\mathrm{Cl}^{-}\right]$and $\left[\mathrm{Na}^{+}\right]$concentrations in sweat for all subjects (measurement accuracy: $\pm 0.02 \mathrm{pCl}$ and $\mathrm{pNa}$ ) 


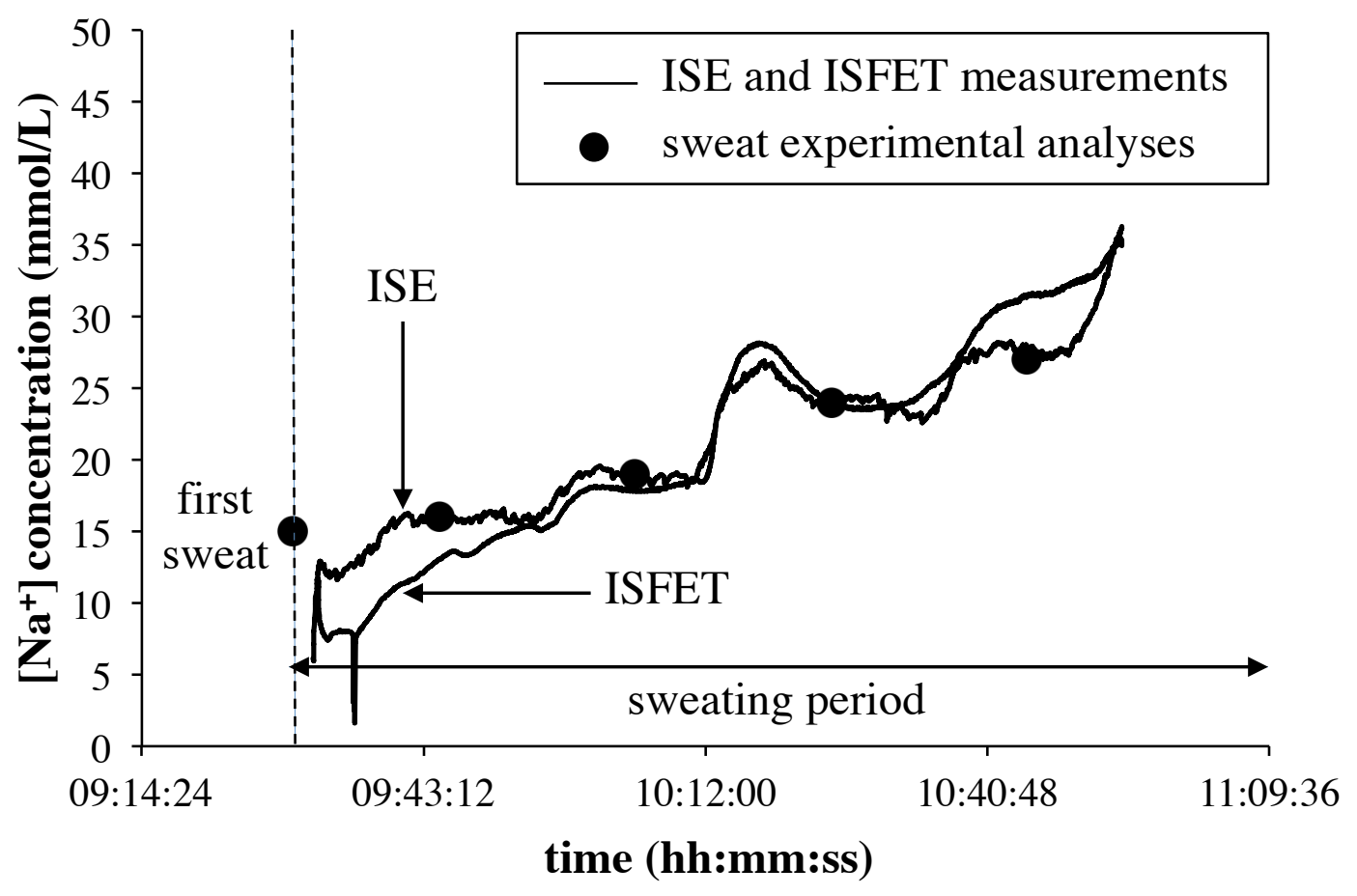

Fig. 12: Monitoring of the sodium concentration $\left[\mathrm{Na}^{+}\right]$in sweat during an ACHT test, comparison of pNa-ISE and pNa-ISFET detection modules with standard chemical analyses (measurement accuracy: $\pm 0.02 \mathrm{pNa}$ ) 


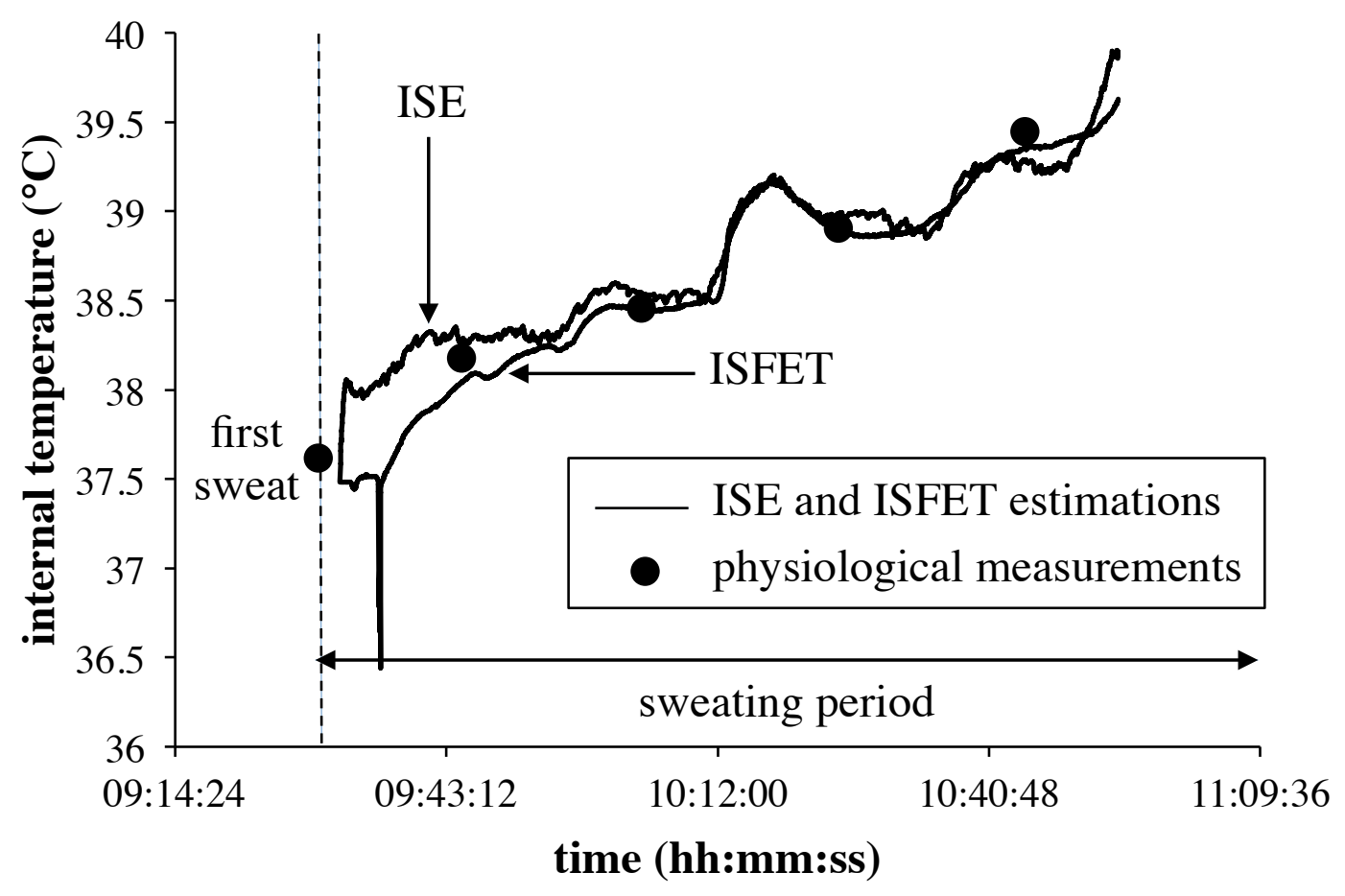

Fig. 13: Study of the internal temperature variations during an ACHT test, comparison with standard rectal measurements (measurement accuracy: $\pm 0.05^{\circ} \mathrm{C}$ ) 